\title{
Biomarkers of nutritional status in honeybee haemolymph: effects of different biotechnical approaches for Varroa destructor treatment and wintering phase
}

\author{
Riccardo CABBri ${ }^{1,2}$, Enea FerlizZA ${ }^{1}$, Antonio NANETTI $^{2}$, Emanuela MonARI ${ }^{3}$, \\ Giulia ANDREANI ${ }^{1}$, Roberta GALUPPI ${ }^{1}$, Gloria IsANI ${ }^{1}$ \\ ${ }^{1}$ Department of Veterinary Medical Sciences, University of Bologna, Via Tolara di sopra, 50, 40064, Ozzano, BO, Italy \\ ${ }^{2}$ Consiglio per la Ricerca in Agricoltura e l'Analisi dell'Economia Agraria, Centro di Ricerca Agricoltura e Ambiente \\ CREA-AA, Rome, Italy \\ ${ }^{3}$ Department of Diagnostic, Clinical and Public Health Medicine, University of Modena and Reggio Emilia, Modena, \\ Italy
}

Received 27 December 2017 - Revised 8 May 2018 - Accepted 20 July 2018

\begin{abstract}
Oxalic acid achieves its maximum efficacy against Varroa destructor during the active season only when coupled with brood manipulation techniques like brood interruption and brood removal. This study aimed to assess the impact of these manipulations on the colony nutritional status and the subsequent wintering phase, focusing on selected haemolymph biomarkers: total proteins (TP), zinc (Zn), vitellogenin (VG) and apolipophorin (APO). Twenty-five days after the manipulations (T1), colonies that underwent brood interruption (BI) stored more $\mathrm{TP}$ and VG than colonies in the brood removal group (BR), with a lower APO percentage, suggesting a lower metabolic effort in summer. In winter, honeybee colonies of all groups reached similar concentrations of the abovementioned parameters, but colonies in the BI group showed a higher population. TP, VG and APO are shown to be promising biomarkers of nutritional status of the colony. Basing on the results obtained, we suggest brood interruption coupled with oxalic acid as the preferred organic method for the control of $V$. destructor in summer.
\end{abstract}

\section{haemolymph proteins / apolipophorin / vitellogenin / nutritional status / Varroa destructor control}

\section{INTRODUCTION}

Biomarkers are a common tool to evaluate health, diagnose disease, monitor therapies and predict outcomes both in human and veterinary medicine (Myers et al. 2017). Few biomarkers have been proposed in apidology and none of them made the way to clinical practice. The activity of some enzymes has been described in literature as biomarker of xenobiotic exposure: AChE activity increases during imidacloprid or clothianidin intoxication (Boily et al. 2013), while CaEs, GST, CAT and ALP activity

Corresponding author: E. Ferlizza, enea.ferlizza2@unibo.it

Manuscript editor: Klaus Hartfelder is modified in bees exposed to thiamethoxam (Badiou-Bénéteau et al. 2012). Regarding nutritional status, haemolymph protein concentration is a good candidate as it relates with the quality of food proteins (De Jong 2009). Moreover, being vitellogenin the main protein of the haemolymph in adult bees (Amdam et al. 2003), its concentration is also a valuable tool to evaluate nutritional status due to its relation with quality (Cremonez et al. 1998) and quantity (Basualdo et al. 2013; Bitondi and Simões 1996) of proteins in the diet.

The nutritional status is of capital importance in the wintering phase to allow colony survival across several months, relying on carbohydrates only. In fact, in temperate climates, honeybees exhibit two different phenotypes: short lived bees, reared from late spring to summer and long-lived 
bees, derived from the generation produced in late summer and autumn (Fluri et al. 1982; Maurizio 1950). The lifespan of the first type is about 2535 days, while the lifespan of the latter can exceed 6 months (Free and Spencer-Booth 1959). The longer lifespan of winter bees is related to a higher haemolymph protein concentration, mainly due to the accumulation of vitellogenin (Amdam et al. 2004a; Fluri et al. 1977, 1982). The long-lived phenotype can be also obtained, regardless of the season, by manipulating the colony into interrupting brood rearing, for example, by caging the queen and thus preventing oviposition (Amdam et al. 2004a; Fluri et al. 1977, 1982; Maurizio 1950). The absence of brood is a prerequisite to achieve maximum efficacy of treatments based on oxalic acid, one of the most widely adopted organic acaricides; in fact, this compound is active only on phoretic mites (Nanetti et al. 2003).

Gregorc et al. (2017) recently studied the efficacy of the two most popular solutions proposed by beekeepers: brood interruption by queen caging and brood removal. Less is known about the impact of these two techniques on the nutritional status of the colony, in the short term and, more importantly, in the wintering phase.

Considering the expected effects of brood manipulations on honeybee physiology, the aim of this paper is to study these modifications in the context of the treatment against Varroa destructor, using a panel of haemolymph biomarkers: total proteins, vitellogenin, apolipophorin and $\mathrm{Zn}$.

\section{MATERIALS AND METHODS}

All the colonies were initially housed at the CREA-AA apiary in Bologna, Italy. All the analyses were performed at the Department of Veterinary Medical Sciences, Alma Mater Studiorum University of Bologna. All reagents were purchased from Thermo Fisher Scientific unless otherwise specified.

\subsection{Study design, sample collection and colony-level traits}

Ten homogeneous Apis mellifera ligustica-derived colonies, naturally infested with $V$. destructor and with similar anamnesis were enrolled in the present study; all of them consisted of nine frames covered with bees and seven frames with brood of variable age, honey and pollen stores sufficient and normal for the season. Five colonies were randomly assigned to group BI that underwent 25 days of brood interruption by queen caging, while the remaining five colonies were assigned to group BR that underwent brood removal. Since in our climatic conditions colonies left untreated for mites usually collapse before winter (Rosenkranz et al. 2010), no control group was used as the death of these colonies would have prevented a complete and useful collection of data. Moreover, colonies with uncontrolled mite infestation can result in increased risk of mite exchange with treated colonies.

All the brood frames of each BR colony were separated from the original colony and used to establish a single nucleus; a small number of bees (ca. 700 workers per comb, approximately three portions of frame) was left on these combs for brood tending. Care was taken during nucleus formation to guarantee that a sufficient amount of honey was present on the brood frames in order to satisfy colony needs. Therefore, from BR group derived two sub-groups: original colony (BR-oc), consisting of adult bees, the queen and frames of stores; nucleus (BR-n), consisting of a small number of adults and the frames with brood and stores. The BR-oc colonies were immediately transferred to another apiary in order to prevent robbery and mite exchange between them (just treated) and the untreated colonies of the other two groups. The second apiary was distant about $3 \mathrm{~km}$ from the first one and was selected for similarity of micro-climatic conditions and trophic sources.

Each treatment was administered to the colonies in absence of brood by trickling a solution of sucrose and API-Bioxal (Chemicals Laif), according to the manufacturer instructions. The BR-oc colonies were treated after 5 days instead of at day 0 to allow them to build new combs and recover the internal dynamics. After 5 days, no receptive brood was present and full treatment efficacy could be achieved. The BR-n and BI hives were treated after 25 days when all the brood was hatched. To ensure the absence of receptive brood in BR-n colonies, natural queen cells were 
removed on day 7 and replaced with artificial ones at day 13. Samplings were performed at three critical time-points: pre-manipulation (T0, end of July), post-manipulation (T1, 25th day, August) and winter (T2, 148th day, December). At T0 and T2, colony-level traits (areas covered with bees, brood, sealed brood and pollen) were estimated. A modified Liebefelder standard method (Delaplane et al. 2013) was used: during the inspection, every face of the frame was divided into six portions and the number of portions covered with each matrix recorded. The number of mites killed by the treatments was used to estimate the $V$. destructor population size, as suggested by Branco et al. (2006). The mites were counted carefully on sticky boards, placed under mesh floor equipped hives, from the beginning of the trial until the 8th day after the treatment.

The evaluation of mite fall started at day 0 for the colonies of all groups and continued until day 33 for the colonies of BI and BR-n groups (25 days of natural mite fall, until colonies were broodless, and 8 days of treatment effect) and until day 13 for the colonies of BR-oc group ( 5 days of natural mite fall +
8 days of treatment effect). The estimation of the $V$. destructor population of the colonies of BR group resulted from the sum of the respective BR-n and BR-oc colonies.

The graphic timeline of the field trial is reported in Figure 1.

\subsection{Haemolymph collection}

For each colony, 30 worker bees were collected between the last brood frame and the stores as suggested by van der Steen et al. (2016). At T1 when no brood was present in BR-n and BI colonies, bees were collected between a store frame and the adjacent frame where brood is expected to be in presence of a fertile queen. Worker honeybees were narcotised with gaseous $\mathrm{CO}_{2}$, held between forceps by the thorax while a glass disposable graduated microcapillary (125 mm length, accuracy $\pm 0.30 \%$, reproducibility $\pm 0.6 \%$, Blaubrand $($ ) was inserted between fourth and fifth tergite. Two microliters of transparent uncontaminated haemolymph were collected from each bee. Haemolymph samples collected from 30 specimens were pooled together,

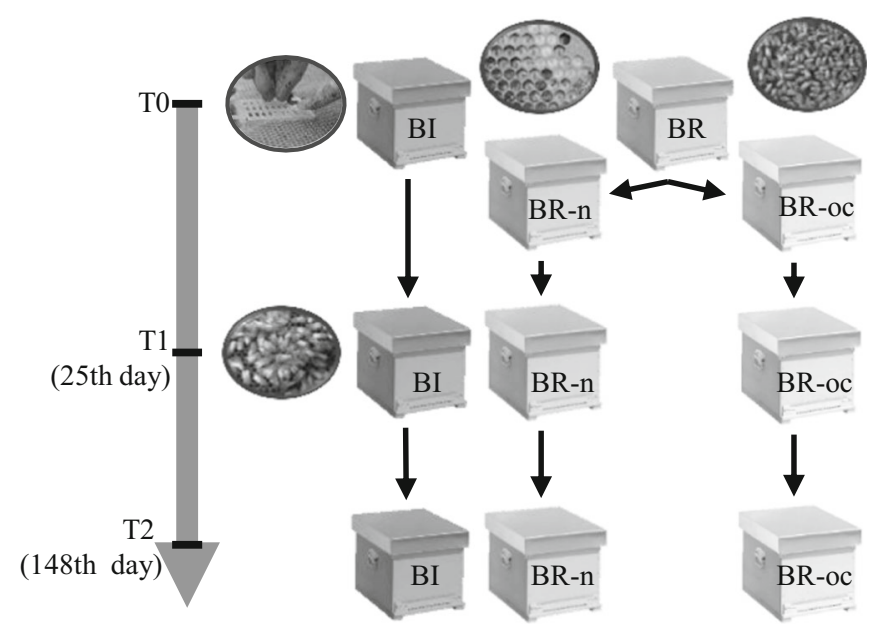

Figure 1 Graphical timeline of the field trial. At T0 (July), colony-level traits inspection and haemolymph collection, queen caging on BI, brood removal on BR establishing BR-n and BR-oc and chemical treatment on BR-oc were performed. At T1 (August), haemolymph collection, queen releasing, and chemical treatment on BI and BR-n were performed. At T2 (December), colony-level traits inspection and haemolymph collection were performed. BI, brood interruption; BR, brood removal; BR-n, nucleus; BR-oc, original colony. 
added with glutathione to a final concentration of $0.1 \% \mathrm{w} / v$ (L-glutathione reduced, Sigma) centrifuged at $3000 \mathrm{~g}$ for $15 \mathrm{~min}$ in order to separate the cells and stored at $-80^{\circ} \mathrm{C}$ for subsequent analysis.

\subsection{Total protein and $\mathrm{Zn}$ analysis}

Total protein (TP) concentration was measured by the Bradford method (Coomassie protein assay) following manufacturer instruction.

The quantification of $\mathrm{Zn}$ was conducted by graphite furnace atomic absorption spectroscopy (GFAAS) (Varian Spectra AA 20 Plus) using palladium, magnesium and EDTA matrix modification with high temperature pyrolysis (Stevens et al. 2017). The haemolymph samples were centrifuged into small tubes at $3000 \mathrm{~g}$ for $15 \mathrm{~min}$ to avoid possible solid material and $2.5 \mu \mathrm{L}$ were dissolved in $1000 \mu \mathrm{L} 0.1 \% \mathrm{Pd} / \mathrm{Mg} / \mathrm{EDTA}$ matrix modifier for the estimation of $\mathrm{Zn}$ concentration.

\subsection{SDS-PAGE}

For each sample, $3 \mu \mathrm{g}$ of proteins were loaded and analysed with the protocol that assured the best protein separation in our experimental conditions (4-12\% gradient gels, in MOPS buffer; NuPAGE, Invitrogen). The gels were stained with Coomassie G250 compatible with mass spectrometry analysis, digitalised by ChemiDoc ${ }^{\mathrm{TM} M P}$ (BioRad) and the pherograms obtained using the ImageLab 5.2.1 software (BioRad). The software determines the volume of each protein band through the analysis of the pixel values in the digital image, meaning as volume the sum of all the pixel intensities within the band boundaries. The band volumes were subsequently compared to the entire volume of the lane and the relative abundance of each protein band was reported as percentage, representing therefore the respective relative abundance as a percentage of the total proteins. The concentration of vitellogenin and apolipophorin expressed as $\mathrm{mg} / \mathrm{mL}$ was obtained by multiplying the total protein concentration by the corresponding relative abundance in percentage.

\subsection{Protein identification by mass spectrometry}

The bands whose molecular weight corresponded to vitellogenin $(180 \mathrm{kDa})$ and apolipophorins $(250 \mathrm{kDa})$ were cut from the gels, digested in-gel with trypsin and finally analysed by a Nano LC-CHIP-MS system (ESI-Q-TOF 6520; Agilent Technologies) as previously described (Bellei et al. 2013). Raw mass spectrometry data were processed to obtain the Mascot generic files for database searching. Since the honeybee haemolymph protein database is not well annotated, a broader taxonomy was selected for identification to be based on sequence homology. Protein identification peak lists were generated using the Mascot search engine (http://mascot.cigs.unimo.it/mascot) against the UniProt database (UniProt.org) specifying the following parameters: all entries, parent ion tolerance $\pm 40 \mathrm{ppm}, \mathrm{MS} / \mathrm{MS}$ error tolerance $\pm 0.120 \mathrm{Da}$, alkylated cysteine as fixed modification and oxidised methionine as variable modification and two potential missed trypsin cleavages. Proteins with a score $>80$ or identified with at least two or more significant sequences were selected. The significant threshold in Mascot searches was set to obtain a false discovery rate $<5 \%$ (5\% probability of false match for each protein with a score above 80).

\subsection{Statistical analysis}

Statistical analysis was performed with the $\mathrm{R}$ software (3.2.5). Data are reported as mean (M) and standard deviation (SD). Normal distribution was tested by the Shapiro-Wilk normality test. Correlation between laboratory (TP, Zn, VG, APO) and colony-level traits (bees, total brood, sealed brood, pollen, V. destructor population size ) was performed by Pearson's correlation test. Two-way ANOVA for repeated measures was performed to evaluate the effect of the interaction of the factors group and time on the laboratory parameters. One-way ANOVA with Tukey's post hoc test for pairwise comparison was performed to evaluate differences among groups (BI, BR-oc, BR-n) within time-points (T0, T1, T2) for colonylevel traits and laboratory parameter or among 
time-points within groups for laboratory parameters. Paired $t$ test was performed to evaluate differences between time-points (T0 and T2) within groups for colony-level traits and to evaluate differences between the groups BI and BR at T0. Values of $P<0.05$ were considered statistically significant.

\section{RESULTS}

\subsection{Colony-level traits}

Data on bees, total brood, sealed brood and pollen are reported in Table I. At T0, there were no statistically significant differences between BI and BR. Also $V$. destructor population size did not show significant differences between $\mathrm{BI}(M=$ 2691, $\mathrm{SD}=2070)$ and $\mathrm{BR}(M=2823, \mathrm{SD}=$ 1202). At T2, only the parameter bees differed significantly between groups $(F[2,12]=7.35$, $P=0.008)$; portions of the frame covered with bees were significantly higher in the colonies of
BI group $(M=45.9, \mathrm{SD}=14.08)$ than those from BR-oc group $(M=20.8, \mathrm{SD}=4.42)$.

Regarding differences between $\mathrm{T} 0$ and $\mathrm{T} 2$, all the parameters showed a significant decrease in the wintering phase (T2).

\subsection{Total protein and $\mathrm{Zn}$ concentrations}

Total protein and $\mathrm{Zn}$ concentrations in honeybee haemolymph are reported in Figure 2 and Table II. TP ranged from 12.4 at $\mathrm{T} 0$ to $33.7 \mathrm{mg} / \mathrm{mL}$ at $\mathrm{T} 2$, while $\mathrm{Zn}$ from 2.7 at $\mathrm{T} 0$ to $4.8 \mu \mathrm{g} / \mathrm{mL}$ at $\mathrm{T} 2$.

A two-way analysis of variance showed that the effect of the interaction between time and group on TP was significant $(F[2,11]=4.302$, $P=0.041670)$.

As regards significant differences among groups, at $\mathrm{T} 0$ and $\mathrm{T} 2$, there were no significant differences. At T1, TP concentration differed significantly between groups $(F[2,12]=33.38, P=$ $1.25 \mathrm{e}-05)$; protein concentration was significantly higher in the colonies of BI group $(M=31.72$,

Table I. Bees, total brood, sealed brood and pollen evaluated at T0 and T2 following a modified Liebefeld method (Delaplane et al. 2013). Data are reported in portions of frame and as mean $\pm \operatorname{SD}(n=5)$.

\begin{tabular}{llll}
\hline Bees (portions of frame) & Group/time & T0 & T2 \\
& BI & $100.8 \pm 26.4 \mathrm{~A} \mathrm{a}$ & $45.9 \pm 12.6 \mathrm{~A} \mathrm{~b}$ \\
& BR-n & $112.6 \pm 34.8 \mathrm{~A} \mathrm{a}$ & $33.6 \pm 9.1 \mathrm{AB} \mathrm{b}$ \\
BR-oc & $112.6 \pm 34.8 \mathrm{~A} \mathrm{a}^{\dagger}$ & $20.8 \pm 4.0 \mathrm{~B} \mathrm{~b}$ \\
Total brood (portions of frame) & Group/time & T0 & T2 \\
& BI & $49.5 \pm 7.6 \mathrm{~A} \mathrm{a}$ & $4.9 \pm 4.4 \mathrm{~A} \mathrm{~b}$ \\
& BR-n & $60.7 \pm 10.9 \mathrm{~A} \mathrm{a}^{\dagger}$ & $3.8 \pm 4.2 \mathrm{~A} \mathrm{~b}$ \\
Sealed brood (portions of frame) & BR-oc & $60.7 \pm 10.9 \mathrm{~A} \mathrm{a}^{\dagger}$ & $0.4 \pm 0.8 \mathrm{~A} \mathrm{~b}$ \\
& Group/time & T0 & T2 \\
& BI & $34.8 \pm 5.1 \mathrm{~A} \mathrm{a}$ & $4.1 \pm 3.8 \mathrm{~A} \mathrm{~b}$ \\
Pollen (portions of frame) & BR-n & $39.5 \pm 6.9 \mathrm{~A} \mathrm{a}^{\dagger}$ & $3.0 \pm 3.3 \mathrm{~A} \mathrm{~b}$ \\
& BR-oc & $39.5 \pm 6.9 \mathrm{~A} \mathrm{a}^{\dagger}$ & $0.4 \pm 0.8 \mathrm{~A} \mathrm{~b}$ \\
& Group/time & T0 & T2 \\
& BI & $5.7 \pm 4.6 \mathrm{~A} \mathrm{a}$ & $0.6 \pm 0.5 \mathrm{~A} \mathrm{~b}$ \\
& BR-n & $7.0 \pm 3.2 \mathrm{~A} \mathrm{a}^{+}$ & $0.2 \pm 0.2 \mathrm{~A} \mathrm{~b}$ \\
& BR-oc & $7.0 \pm 3.2 \mathrm{~A} \mathrm{a}^{\dagger}$ & $0.1 \pm 0.2 \mathrm{~A} \mathrm{~b}$ \\
\hline
\end{tabular}

Different lower case letters within rows indicate significant differences $(P<0.05)$ between time-points within groups. Different capital letters in the column indicate significant differences $(P<0.05)$ among groups within time-points

$B I$ brood interruption, $B R$ brood removal, $B R-n$ nucleus, $B R-o c$ original colony

$\dagger$ Since BR-n derived from BR-oc after the sampling at T0, the values of the analytes at T0 are the same and refer to the BR colonies before the removal of the brood frames 

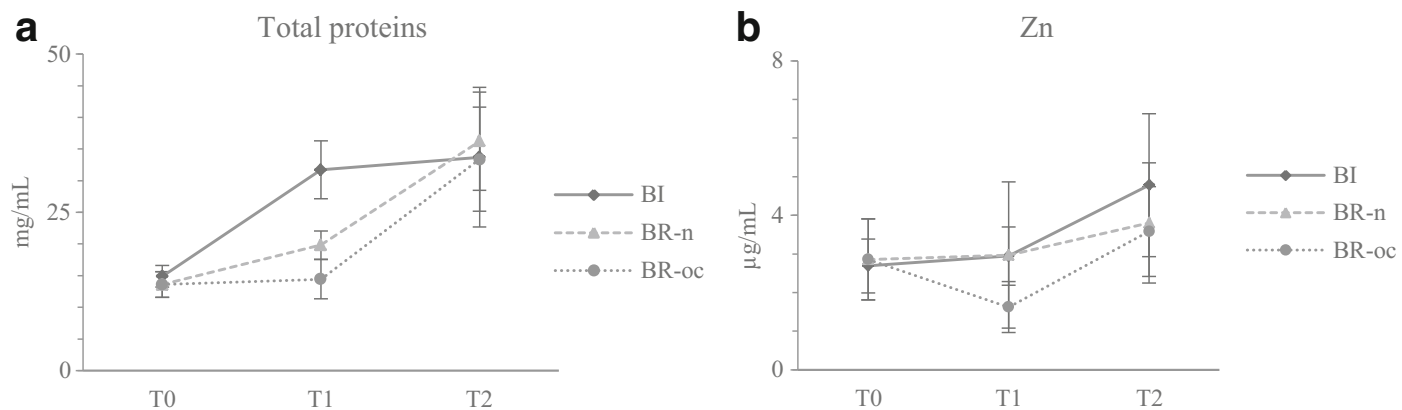

Figure 2 Variations of total protein and $\mathrm{Zn}$ concentrations in honeybee haemolymph at different time-points. Data are expressed in a $\mathrm{mg} / \mathrm{mL}(\mathrm{TP})$ and $\mathbf{b} \mu \mathrm{g} / \mathrm{mL}$ ( $\mathrm{Zn})$ and reported as mean $\pm \mathrm{SD}(n=5)$. BI, brood interruption; BR-n, nucleus; BR-oc, original colony.

Table II. Total proteins (TP), Zn, vitellogenin (VG) and apolipophorin (APO) determined in honeybee haemolymph at different time-points. Data are reported as mean $\pm \mathrm{SD}(n=5)$.

\begin{tabular}{|c|c|c|c|c|}
\hline \multirow[t]{4}{*}{$\mathrm{TP}, \mathrm{mg} / \mathrm{mL}$} & Group/time & T0 & $\mathrm{T} 1$ & $\mathrm{~T} 2$ \\
\hline & BI & $13.6 \pm 2.9 \mathrm{~A} \mathrm{a}$ & $31.7 \pm 4.1 \mathrm{~A} \mathrm{~b}$ & $33.7 \pm 9.9 \mathrm{~A} \mathrm{~b}$ \\
\hline & BR-n & $12.4 \pm 2.8 \mathrm{~A} \mathrm{a}$ & $19.8 \pm 2.0 \mathrm{~B} \mathrm{a}$ & $30.7 \pm 12.6 \mathrm{~A} \mathrm{~b}$ \\
\hline & BR-oc & $12.4 \pm 2.8 \mathrm{~A} \mathrm{a}^{\dagger}$ & $14.4 \pm 2.8 \mathrm{~B} \mathrm{a}$ & $33.4 \pm 7.3 \mathrm{~A} \mathrm{~b}$ \\
\hline \multirow[t]{4}{*}{$\mathrm{Zn}, \mu \mathrm{g} / \mathrm{mL}$} & Group/time & $\mathrm{T} 0$ & $\mathrm{~T} 1$ & $\mathrm{~T} 2$ \\
\hline & $\mathrm{BI}$ & $2.7 \pm 0.7 \mathrm{~A} \mathrm{a}$ & $2.9 \pm 0.7 \mathrm{~A} \mathrm{a}$ & $4.8 \pm 1.8 \mathrm{~A} \mathrm{a}$ \\
\hline & BR-n & $2.9 \pm 1.1 \mathrm{~A} \mathrm{a}$ & $2.9 \pm 1.9 \mathrm{~A} \mathrm{a}$ & $4.4 \pm 1.2 \mathrm{~A} \mathrm{a}$ \\
\hline & BR-oc & $2.9 \pm 1.1 \mathrm{~A} \mathrm{a}^{\dagger}$ & $1.6 \pm 0.7 \mathrm{~A} \mathrm{a}$ & $4.2 \pm 0.5 \mathrm{~A} \mathrm{a}$ \\
\hline \multirow[t]{4}{*}{$\mathrm{VG}, \mathrm{mg} / \mathrm{mL}$} & Group/time & T0 & $\mathrm{T} 1$ & $\mathrm{~T} 2$ \\
\hline & BI & $3.1 \pm 1.4 \mathrm{~A} \mathrm{a}$ & $12.6 \pm 1.9 \mathrm{~A} \mathrm{~b}$ & $15.0 \pm 5.5 \mathrm{~A} \mathrm{~b}$ \\
\hline & BR-n & $2.8 \pm 1.2 \mathrm{~A} \mathrm{a}$ & $7.0 \pm 1.0 \mathrm{~B} \mathrm{a}$ & $17.0 \pm 4.3 \mathrm{~A} \mathrm{~b}$ \\
\hline & BR-oc & $2.8 \pm 1.2 \mathrm{~A} \mathrm{a}^{\dagger}$ & $4.0 \pm 1.6 \mathrm{C} \mathrm{a}$ & $15.0 \pm 5.0 \mathrm{~A} \mathrm{~b}$ \\
\hline \multirow[t]{4}{*}{$\mathrm{APO}, \mathrm{mg} / \mathrm{mL}$} & Group/time & T0 & $\mathrm{T} 1$ & $\mathrm{~T} 2$ \\
\hline & BI & $3.9 \pm 0.7 \mathrm{~A} \mathrm{a}$ & $5.8 \pm 0.5 \mathrm{~A} \mathrm{~b}$ & $4.3 \pm 0.8 \mathrm{~A} \mathrm{a}$ \\
\hline & BR-n & $3.7 \pm 0.9 \mathrm{~A} \mathrm{a}$ & $4.6 \pm 0.4 \mathrm{~B} \mathrm{a}$ & $4.0 \pm 0.8 \mathrm{~A} \mathrm{a}$ \\
\hline & BR-oc & $3.7 \pm 0.9 \mathrm{~A} \mathrm{a}^{\dagger}$ & $3.5 \pm 0.5 \mathrm{C} \mathrm{a}$ & $3.6 \pm 0.2 \mathrm{~A} \mathrm{a}$ \\
\hline \multirow[t]{4}{*}{$\mathrm{VG}, \%$} & Group/time & T0 & $\mathrm{T} 1$ & $\mathrm{~T} 2$ \\
\hline & BI & $21.5 \pm 6.9 \mathrm{~A} \mathrm{a}$ & $39.5 \pm 2.4 \mathrm{~A} \mathrm{~b}$ & $43.7 \pm 3.5 \mathrm{~A} \mathrm{~b}$ \\
\hline & BR-n & $21.5 \pm 5.9 \mathrm{~A} \mathrm{a}$ & $35.1 \pm 1.6 \mathrm{~A} \mathrm{ab}$ & $46.4 \pm 3.3 \mathrm{~A} \mathrm{~b}$ \\
\hline & BR-oc & $21.5 \pm 5.9 \mathrm{~A} \mathrm{a}^{\dagger}$ & $27.0 \pm 5.2 \mathrm{~B} \mathrm{a}$ & $44.1 \pm 4.1 \mathrm{~A} \mathrm{~b}$ \\
\hline \multirow[t]{4}{*}{$\mathrm{APO}, \%$} & Group/time & T0 & $\mathrm{T} 1$ & $\mathrm{~T} 2$ \\
\hline & BI & $29.7 \pm 5.1 \mathrm{~A} \mathrm{a}$ & $18.5 \pm 1.1 \mathrm{~A} \mathrm{~b}$ & $13.1 \pm 1.9 \mathrm{~A} \mathrm{~b}$ \\
\hline & BR-n & $29.7 \pm 4.2 \mathrm{~A} \mathrm{a}$ & $23.3 \pm 2.1 \mathrm{~B} \mathrm{a}$ & $11.3 \pm 1.6 \mathrm{~A} \mathrm{~b}$ \\
\hline & BR-oc & $29.7 \pm 4.2 \mathrm{~A} \mathrm{a}^{\dagger}$ & $24.5 \pm 1.1 \mathrm{~B} \mathrm{a}$ & $11.1 \pm 1.4 \mathrm{~A} \mathrm{~b}$ \\
\hline
\end{tabular}

Different lower case letters within rows indicate significant differences $(P<0.05)$ among time-points within groups. Different capital letters in the column indicate significant differences $(P<0.05)$ among groups within time-points

$B I$ brood interruption, $B R-n$ brood removal nucleus, $B R-o c$ brood removal original colony

$\dagger$ Since BR-n derived from BR-oc after the sampling at $\mathrm{T} 0$, the values of the analytes at $\mathrm{T} 0$ are the same and refer to the $\mathrm{BR}$ colonies before the removal of the brood frames 

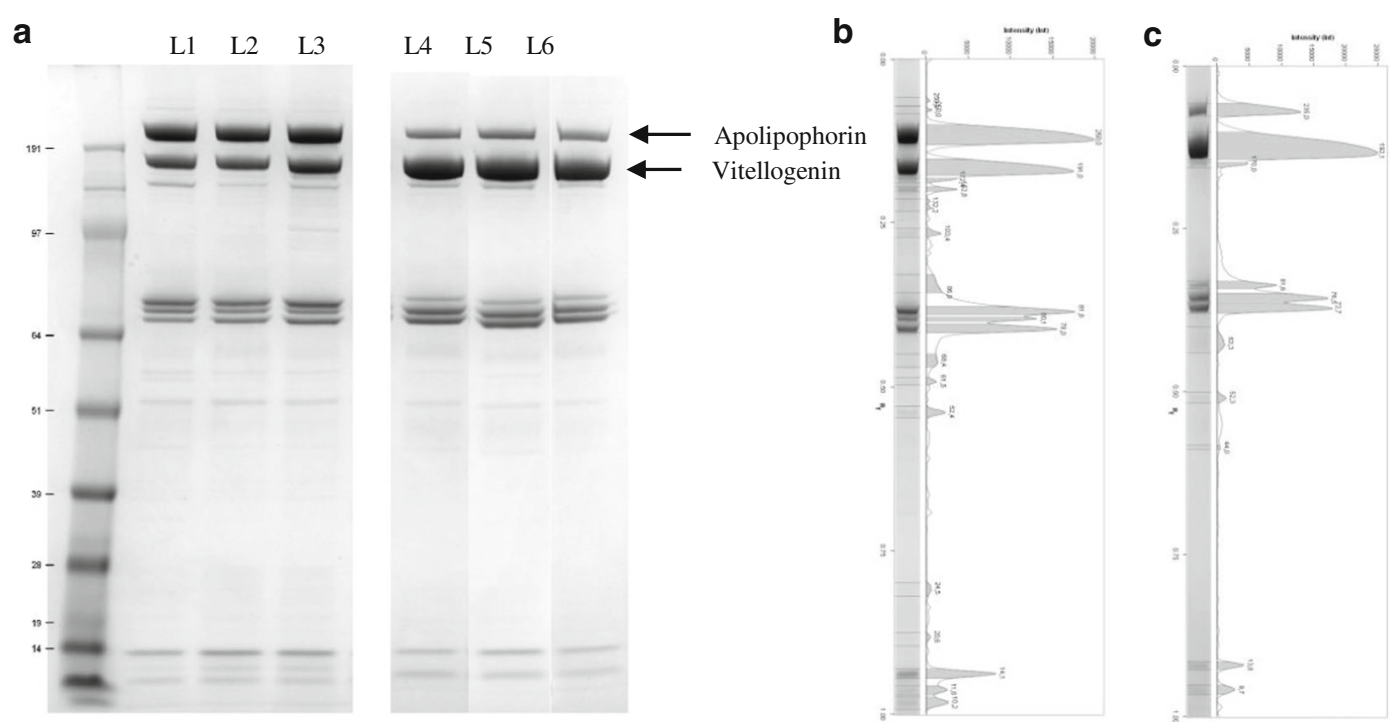

Figure 3 Representative SDS-PAGE gel and pherograms of honeybee haemolymph. a SDS-PAGE: lanes 1 and 2, haemolymph samples from BR group at T0; lane 3, haemolymph sample from BI group at T0; lanes 4, 5 and 6, haemolymph samples from BR-n, BR-oc and BI, respectively, at T2. b Pherogram of lane 3 (BI, T0). c Pherogram of lane 6 (BI, T2). BI, brood interruption; BR, brood removal; BR-n, nucleus; BR-oc, original colony.

$\mathrm{SD}=4.55)$ than in those from BR-oc group $(M=$ 14.44, $\mathrm{SD}=3.09)$ and BR-n group $(M=19.84$, $\mathrm{SD}=2.22$ ).

An analysis of variance showed also that the effect of time on TP was significant for group BI $(F[2,11]=8.71, P=0.0054), \mathrm{BR}-\mathrm{n}$ $(F[1,7]=026.06, P=0.000108)$ and BR-oc, $(F[2,11]=20.67, P=0.000188)$. Protein concentration was significantly higher at $\mathrm{T} 1(M=31.72$, $\mathrm{SD}=4.55)$ and $\mathrm{T} 2(M=33.70, \mathrm{SD}=11.03)$ than at $\mathrm{T} 0(M=14.90, \mathrm{SD}=1.72)$ for $\mathrm{BI}$ colonies and significantly higher at $\mathrm{T} 2(M=36.25, \mathrm{SD}=7.75)$ than $\mathrm{T} 1(M=19.84, \mathrm{SD}=2.22)$ and $\mathrm{T} 0(M=$ $13.60, \mathrm{SD}=2.02$ ) for BR-n. Same as BR-n can be said about BR-oc with T2 $(M=33.40, \mathrm{SD}=$ $8.21)$ higher than $\mathrm{T} 0(M=13.60, \mathrm{SD}=2.019901)$ and T1 $(M=14.44, \mathrm{SD}=3.086746)$.

Regarding $\mathrm{Zn}$, there were no significant differences among groups or among time-points.

\subsection{Protein separation by SDS-PAGE}

The optimised protocol resulted in the separation of different protein bands in samples of worker honeybee haemolymph. All samples presented a similar pattern characterised by the presence of five most abundant protein bands (Figure 3). The two most consistent bands were identified by mass spectrometry: the band at an apparent molecular weight $>200 \mathrm{kDa}$ was unambiguously identified as apolipophorin (APO), while the band at $180 \mathrm{kDa}$ was identified as vitellogenin. Other important protein bands were present at 72,70 and $67 \mathrm{kDa}$ in all the analysed samples. Less abundant bands were present in particular at molecular weights less than $60 \mathrm{kDa}$.

\subsection{Percentage and concentration of VG and APO}

Data on VG and APO are reported in Figures 4 and 5, respectively, and in Table II. VG concentration in haemolymph ranged from 2.8 to $17 \mathrm{mg} /$ $\mathrm{mL}$ accounting for $43-46 \%$ of haemolymph TP at the wintering phase (T2). On the contrary, APO concentration showed minor variations ranging from 3.6 to $5.8 \mathrm{mg} / \mathrm{mL}$ and at $\mathrm{T} 2$ this protein represented only $11-13 \%$. When evaluating the differences among BI, BR-n and BR-oc within each time-point, at $\mathrm{T} 0$ and $\mathrm{T} 2$, there were no significant differences. 

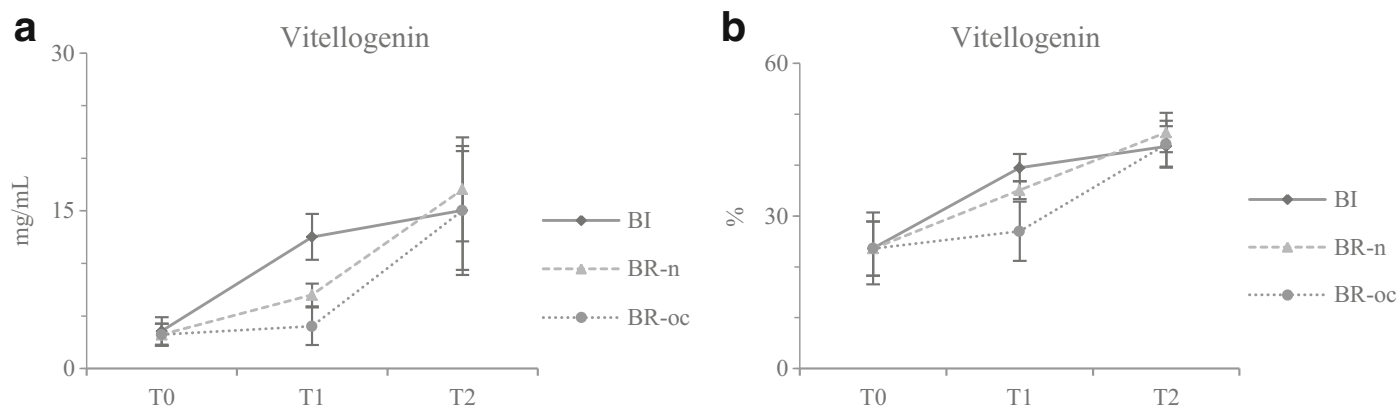

Figure 4 Variations of vitellogenin in honeybee haemolymph at different time-points. Data are expressed in a $\mathrm{mg} /$ $\mathrm{mL}$ and $\mathbf{b}$ percentage and are reported as mean $\pm \mathrm{SD}(n=5)$. BI, brood interruption; BR-n, nucleus; BR-oc, original colony.

A two-way analysis of variance showed that the effect of the interaction between time and group was significant on $\mathrm{VG}$ percentage $(F[2,11]=14.55, P=0.000813)$ and APO percentage $(F[2,11]=19.61, P=0.000236)$ but not on VG concentration and APO concentration.

At T1, after the manipulations, there were statistically significant differences among groups regarding VG percentage $(F[2,12]=13.54, P=$ $0.000837)$ and $\mathrm{VG}$ concentration $(F[2,12]=$ $\left.30.94, P=1.84 \mathrm{e}^{-}-05\right)$. VG concentration in colonies of the group BR-oc $(M=26.98, \mathrm{SD}=5.84)$ was significantly lower than that of groups BR-n $(M=35.08, \mathrm{SD}=1.79)$ and $\mathrm{BI}(M=39.48, \mathrm{SD}=$ 2.68). On the other hand, VG concentration differed among all the groups with the highest value in $\mathrm{BI}$ group $(M=12.55, \mathrm{SD}=2.18)$ followed by

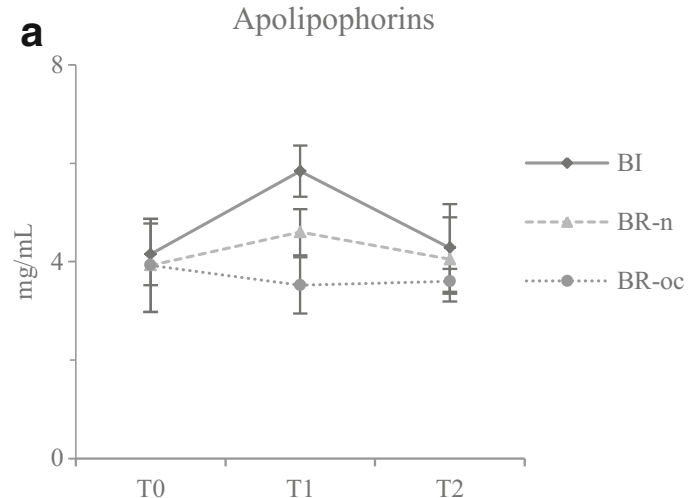

BR-n group $(M=6.99, \mathrm{SD}=1.08)$ and $\mathrm{BR}-\mathrm{oc}$ $(M=4.03, \mathrm{SD}=1.78)$. A similar pattern could be observed regarding APO percentage ( $\left.F[2,12], P=6.51 \mathrm{e}^{-05}\right)$, with highest value in BI group $(M=5.83, \mathrm{SD}=0.53)$ followed by BR-n group $(M=4.60, \mathrm{SD}=0.45)$ and $\mathrm{BR}$-oc $(M=3.50, \mathrm{SD}=0.60)$.

APO percentage showed also significant differences among groups $(F[2,12]=17.87, P=$ $0.000252)$. In this case, the value for the BI group $(\mathrm{M}=18.50, \mathrm{SD}=1.27)$ was significantly lower than those from BR-n $(M=23.32, \mathrm{SD}=2.30)$ and BR-oc $(M=24.46, \mathrm{SD}=1.22)$.

Regarding variations among time-points, there were significant differences in VG percentage for BI group $(F[2,11]=22.1, P=0.00014)$, BR-n $(F[2,11]=36.41, P=2.57 \mathrm{e}-05)$ and BR-oc

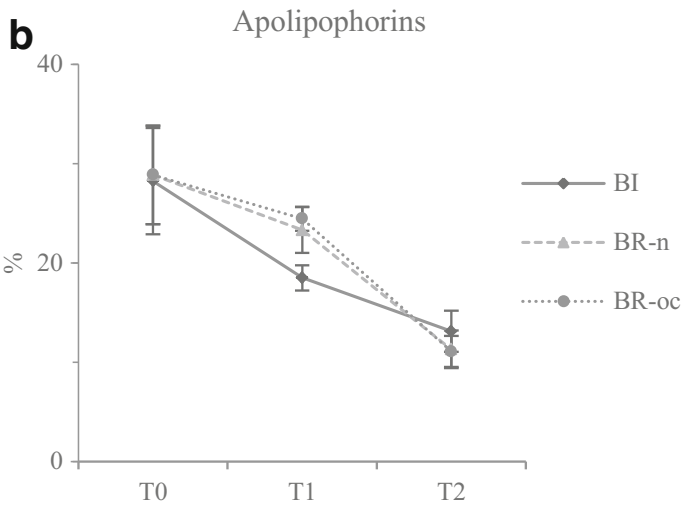

Figure 5 Variations of apolipophorin in honeybee haemolymph groups at different time-points. Data are expressed in $\mathbf{a} \mathrm{mg} / \mathrm{mL}$ and $\mathbf{b}$ percentage and are reported as mean $\pm \mathrm{SD}(n=5)$. BI brood interruption; BR-n, brood removal nucleus; BR-oc, brood removal original colony. 
$(F[2,11]=20.46, P=0.000196)$. In BI group, the percentage was significantly higher at T1 $(M=$ 39.48, $\mathrm{SD}=2.68)$ and $\mathrm{T} 2(M=43.68, \mathrm{SD}=3.97)$ than at $\mathrm{T} 0(M=23.63, \mathrm{SD}=7.03)$. In BR-n group, all the time-points differed significantly from each other with, in ascending order, T0 $(M=23.60, \mathrm{SD}=$ 5.33), $\mathrm{T} 1(M=35.08, \mathrm{SD}=1.79)$ and $\mathrm{T} 2(M=$ $46.43, \mathrm{SD}=3.87)$. A totally different pattern can be observed in BR-oc group with only the percentage at $\mathrm{T} 2(M=44.12, \mathrm{SD}=4.62)$ significantly higher than those at $\mathrm{T} 0(M=23.60, \mathrm{SD}=5.33)$ and $\mathrm{T} 1(M=26.98, \mathrm{SD}=5.84)$.

There were significant differences in VG concentration for BI group $(F[2,11]=9.85, P=$ $0.00353)$, BR-n $(F[2,11]=36.41, P=2.57 \mathrm{e}-05)$ and BR-oc $(F[2,11]=20.46, P=0.000196)$. In $\mathrm{BI}$ group, the percentage was significantly higher at $\mathrm{T} 1(M=12.55, \mathrm{SD}=2.18)$ and $\mathrm{T} 2(M=15.03$, $\mathrm{SD}=6.14)$ than at $\mathrm{T} 0(M=3.58, \mathrm{SD}=1.31)$. In BR-n group, only $\mathrm{T} 2(M=36.25, \mathrm{SD}=7.75)$ differed significantly from T0 $(M=13.60, \mathrm{SD}=$ $2.02)$ and $\mathrm{T} 1 \quad(M=19.84, \mathrm{SD}=2.22)$, while in BR-oc group, only the percentage at T2 $(M=$ 15.03, $\mathrm{SD}=5.62$ ) was significantly higher than those at T0 $(M=3.23, \mathrm{SD}=1.04)$ and $\mathrm{T} 1(M=$ 4.03, $\mathrm{SD}=1.78)$.

APO percentage showed also significant differences among time-points in BI group $(F[2,11]=$ 25.72, $P=7.12 \mathrm{e}-05)$, BR-n $(F[2,11]=30.61$, $P=5.46 \mathrm{e}-05)$ and BR-oc $(F[2,11]=48.87, P=$ $3.37 \mathrm{e}-06)$. In $\mathrm{BI}$ group, the percentages at $\mathrm{T} 1$ $(M=18.50, \mathrm{SD}=1.27)$ and $\mathrm{T} 2(M=13.12, \mathrm{SD}=$ 2.09) were significantly lower than that at T0 $(M=28.25, \mathrm{SD}=5.36)$.

In BR-n group, only the percentage at $\mathrm{T} 2(M=$ $11.30, \mathrm{SD}=1.89)$ was significantly lower than those at $\mathrm{T} 0(M=28.88, \mathrm{SD}=4.97)$ and $\mathrm{T} 1$ $(M=23.320, \mathrm{SD}=2.30)$.

The same pattern can be observed for BR-oc group where only the percentage at $\mathrm{T} 2(M=$ $11.08, \mathrm{SD}=1.57$ ) was significantly lower than those at $\mathrm{T} 0(M=28.88, \mathrm{SD}=4.97)$ and $\mathrm{T} 1$ $(M=24.460, \mathrm{SD}=1.22)$.

Correlations were studied using all the values in the dataset, independently of treatment groups or time of sampling. There were significant positive correlations between TP and VG concentration $(r=0.991, P<0.01)$, TP and VG percentage $(r=0.89, P<0.01)$, TP and $\mathrm{Zn}$ concentration $(r=0.533 P<0.05), \mathrm{Zn}$ and $\mathrm{VG}$ concentration $(r=0.55, P<0.01)$ and $\mathrm{Zn}$ and $\mathrm{VG}$ percentage $(r=0.526, P<0.05)$. There were significant negative correlations between APO percentage and $\mathrm{TP}(r=-0.839, P<0.01), \mathrm{Zn}(r=-0.498, P<$ $0.05)$, VG concentration $(r=-0.864, P<0.01)$ and VG percentage $(r=-0.929, P<0.01)$. Regarding the correlation between field and laboratory data, total brood was negatively correlated with TP $(r=-0.75, P<0.01)$, VG concentration $(r=-0.77, P<0.01)$ and VG percentage $(r=-$ $0.72, P<0.01)$ and positively correlated with APO percentage $(r=0.867, P<0.01)$. Similarly, sealed brood was negatively correlated with TP $(r=-0.77, P<0.01)$, VG concentration $(r=-$ $0.79, P<0.01)$ and VG percentage $(r=-0.73$, $P<0.01)$ and positively with APO percentage $(r=0.874, P<0.01)$.

\section{DISCUSSION}

The aim of the present paper was to assess the impact of the manipulations needed for the summer $V$. destructor treatment (T1) and the subsequent wintering phase (T2) on the colony nutritional status, using an innovative panel of biomarkers.

At $\mathrm{T} 1$, the adopted manipulations determined a different impact on colony nutritional status: hives from the BI group showed significantly higher TP concentration, VG concentration and percentage than the other groups. The consistency among the above-mentioned biomarkers is not surprising since vitellogenin is the most abundant protein in honeybee haemolymph (Amdam et al. 2003). In insects, this protein plays an important role in lipid transport, immune function, longevity and production of royal jelly (Blacklock and Ryan 1994; Amdam et al. 2004a; Havukainen et al. 2013). Therefore, the accumulation of vitellogenin in haemolymph of workers subjected to gradual reduction of brood caring is predictable. In fact, colonies of BI and BR-n groups, where oviposition was interrupted, showed significantly higher concentration and percentage of vitellogenin than colonies of BR-oc group where oviposition continued throughout summer.

Notably, only colonies of BI group reached in summer TP and VG concentrations comparable to those found in winter. This confirms previous 
findings regarding the possibility of obtaining winter bees in summer by controlling brood rearing (Amdam et al. 2004a; Fluri et al. 1977, 1982; Maurizio 1950). This phenomenon probably resembles what physiologically happens in temperate zones when winter is approaching: during autumn, the unfavourable environmental conditions drive the colony to cease brood rearing and store protein in their fat bodies (Fluri et al. 1982). A further evidence of the relationship between a specific nutritional status and the presence of brood is provided by the correlations found in the present study between brood amount (total and sealed) and TP, VG concentration and $\mathrm{VG} \%$.

Brood interruption is often considered with concern by beekeepers, due to the loss of 25 days of queen oviposition. However, considering that Amdam et al. (2005a) found a positive correlation between vitellogenin concentration and worker longevity and that longevity is a key factor for colonies (DeGrandi-Hoffman and Curry 2004), it is possible that the loss of oviposition is at least partially compensated by the increase in honeybee longevity.

BI differed significantly from the others groups also regarding APO \%: the percentage at T1 was significantly lower than values found in the other groups, and from the percentage found at T0, approaching the winter value determined at T2. Apolipophorins are the major lipoproteins in insects and their presence in haemolymph is closely related to lipid mobilisation (Robbs et al. 1985). According to Arrese and Soulages (2010), the mobilisation of lipids in insects can be related to several causes, including embryogenesis, immune response and starvation. In the present study, the cause of the higher lipid mobilisation observed in BR-n and BR-oc is probably related to nutritional stress. In fact, subgroup BR-n underwent depletion of most of adult bees with their endogenous reserves, whose function is to produce royal jelly to feed the young larvae (Haydak 1970), and of part of the pollen reserves, contained mainly in the frames left in the original colony. At the same time, the subgroup BR-oc is deprived of part of honey stores contained in the removed brood frames and of drawn combs; therefore, it is forced to build new combs, an energetically expensive task. Schulz et al. (1998) showed how carbohydrate starvation causes a precocious transition from house bees to foragers. Moreover, Huang and Robinson (1996) demonstrated that wax deprivation, obtained by removing drawn combs, produced the same effect. Interestingly this physiological transition has been correlated to a decrease in the vitellogenin endogenous reserves and with a precocious senescence (Amdam et al. 2003). It is possible that the manipulation elicited an effect on the nutritional status both directly and indirectly via an alteration of the division of labour in the colony. In addition, the recovery of the nutritional stress is probably impaired by the late summer condition of the zone where the experiment took place, characterised by dry climate with scarce flowering.

In honeybee colonies, there is a strict relation between nutritional status and immunity (Münch et al. 2013). Basualdo et al. (2014) showed that the use of "beebread" (pollen supplemented with enzymes and bacteria of the salivary bee glands, fermented and stored in honey cells) promotes a significant increase of haemolymph total proteins and a higher survival in bees subjected to artificial infection by Nosema ceranae compared to honeybee fed with a protein substitute. This supports the hypothesis that bee resilience to pathogens is related to the protein content in haemolymph. In this context, the infestation by $V$. destructor could play an important role. In particular, a negative effect of this parasite on the ability of bees in accumulating vitellogenin has been reported (Amdam et al. 2004b). Differently, in the present paper, $V$. destructor infestation did not correlate with vitellogenin. The discrepancy could be ascribed to the fact that Amdam et al. (2004b) evaluated the effect of the parasite on single bees individually, while in our study, the evaluation was performed on the entire colony. Moreover, the relatively low level of infestation in the colonies, that was also not different among groups, could have been not sufficient to influence the concentration of vitellogenin in haemolymph.

Vitellogenin is the main haemolymph $\mathrm{Zn}$ binding molecule and a relationship between this protein, haemolymph $\mathrm{Zn}$ concentration and cellular immunity has been suggested (Amdam et al. 2004a). Our study adds more evidence of the positive relation between vitellogenin and circulating $\mathrm{Zn}$.

Strict relation between $\mathrm{Zn}$ and immune function in insects has been demonstrated also in Manduca sexta (Willott and Tran 2002). The 
levels found in our study are similar to those reported by Amdam et al. (2004b) in foragers and lower than the levels found in hive bees and winter bees.

At winter time (T2), no significant differences in total proteins, vitellogenin and apolipophorinVG and VG concentration among the three groups were measured, suggesting that bees of all the colonies were able to store similar protein reserves. The data obtained in the present study are in accord with those reported for winter bees by other authors (van der Steen et al. 2016). Interestingly, hive population was the only parameter showing significant differences among groups at T2. While BI and BR-n groups showed a population in line with the expectations for Apis mellifera ligustica colonies, colonies of the BR-oc group overwintered with a mean population of only approximately 5000 adult bees, roughly corresponding to three Dadant-Blatt frames covered with bees. Such small cluster is very similar to that studied by Harbo (1983) (approximately 4400 bees) which is reported to be less capable in thermoregulation and less efficient in the use of reserves; indeed the single bee consumption of honey is inversely correlated with the number of individuals in the cluster itself. Despite the low population, all the colonies of BRoc group survived until next spring, thanks to the relatively warm winter of 2015 .

In conclusion, the innovative panel of biomarkers presented in this study, including also for the first time apolipophorin, proved to be useful in assessing the impact of brood manipulation on the colonies. Our data suggest that the duplication of the colonies by brood removal could determine a greater risk of colony losses facing the winter, due to the impact on endogenous stores in summer and on hive population in winter. Supplemental feeding might be an option to mitigate the negative effects of brood removal even if scientific consensus on pollen substitutes is lacking. The better nutritional status obtained with brood interruption in summer should be further investigated in order to confirm the supposed benefits on bee immunity and resilience to pathogens.

For the above-mentioned reasons, we suggest the brood interruption protocol as an organic, effective and less stressful method to control $V$. destructor in summer.

\section{ACKNOWLEDGMENTS}

The authors acknowledge CREA-AA for providing honeybee colonies and facilities, Elisa Bellei and Aurora Cuoghi for the help in mass spectrometry identification of proteins and Diego Bucci for the help with the statistical analysis.

\section{FUNDING}

This study was supported by a grant from the University of Bologna (RFO) to GI and RG and by a grant from Eva Crane Trust (ECTA_20161205).

\section{COMPLIANCE WITH ETHICAL STANDARDS}

\section{AUTHORS' CONTRIBUTION}

RC, GI, RG and AN conceived this research and designed experiments; RC, EF, GA and EM performed experiments and analysis; RC, EF and GI wrote the paper; and RG and GA participated in the revisions of it. All authors read and approved the final manuscript.

Conflict of interest The authors declare that they have no competing interests.

Biomarqueurs de l'état nutritionnel dans l'hémolymphe des abeilles mellifères: effets de différentes approches biotechniques pour le traitement $d u$ Varroa destructor et la phase d'hivernage

protéines de l'hémolymphe / apolipophorine / vitellogénine / état nutritionnel / contrôle de V. destructor

Biomarker des Ernährungszustands in der Hämolymphe von Honigbienen: Effekte unterschiedlicher biotechnischer Verfahren zur Behandlung gegen Varroa destructor treatment und die Überwinterung

Hämolymphproteine / Apolipophorin / Vitellogenin / Ernährungszustand / V. destructor Kontrolle

\section{REFERENCES}

Amdam, G. V, Norberg, K., Hagen, A., Omholt, S.W., 2003. Social exploitation of vitellogenin. Proc. Natl. Acad. Sci. U. S. A. 100 (4), 1799-1802. 
Amdam, G. V., Simões, Z.L.P., Hagen, A., Norberg, K., Schrøder, K., Mikkelsen, Ø., Kirkwood, T.B.L., Omholt, S.W., 2004a. Hormonal control of the yolk precursor vitellogenin regulates immune function and longevity in honeybees. Exp. Gerontol. 39 (5), 767-773.

Amdam, G. V, Hartfelder, K., Norberg, K., Hagen, A., Omholt, S.W., 2004b. Altered physiology in worker honey bees (Hymenoptera: Apidae) infested with the mite Varroa destructor (Acari: Varroidae): a factor in colony loss during overwintering? J. Econ. Entomol. 97 (3), 741-747.

Amdam, G. V., Norberg, K., Omholt, S.W., Kryger, P., Lourenço, A.P., Bitondi, M.M.G., Simões, Z.L.P., 2005a. Higher vitellogenin concentrations in honey bee workers may be an adaptation to life in temperate climates. Insect. Soc. 52 (4), 316-319.

Arrese, E.L., Soulages, J.L., 2010. Insect fat body: energy, metabolism, and regulation. Annu. Rev. Entomol. 55 (87), 207-225.

Badiou-Bénéteau, A., Carvalho, S.M., Brunet, J.L., Carvalho, G.A., Buleté, A., Giroud, B., Belzunces, L.P., 2012. Development of biomarkers of exposure to xenobiotics in the honey bee Apis mellifera: application to the systemic insecticide thiamethoxam. Ecotoxicol. Environ. Saf. 82, 22-31.

Basualdo, M., Barragán, S., Vanagas, L., García, C., Solana, H., Rodríguez, E., Bedascarrasbure, E., Alaux, C., Ducloz, F., Clauser, D., et al., 2013. Conversion of high and low pollen protein diets into protein in worker honey bees (Hymenoptera: Apidae). J. Econ. Entomol. 106 (4), 1553-1558.

Basualdo, M., Barragán, S., Antúnez, K., 2014. Bee bread increases honeybee haemolymph protein and promote better survival despite of causing higher Nosema ceranae abundance in honeybees. Environ. Microbiol. Rep. 6 (4), 396-400.

Bellei, E., Monari, E., Cuoghi, A., Bergamini, S., Guerzoni, S., Ciccarese, M., Ozben, T., Tomasi, A., Pini, L.A., 2013. Discovery by a proteomic approach of possible early biomarkers of drug-induced nephrotoxicity in medication-overuse headache. J. Headache Pain 14 (1), 6.

Bitondi, M.M.G., Simões, Z.L.P., 1996. The relationship between level of pollen in the diet, vitellogenin and juvenile hormone titres in Africanized Apis mellifera workers. J. Apic. Res. 35 (1), 27-36.

Blacklock, B.J., Ryan, R.O., 1994. Hemolymph lipid transport. Insect Biochem. Mol. Biol. 24 (9), 855-873.

Boily, M., Sarrasin, B., DeBlois, C., Aras, P., Chagnon, M., 2013. Acetylcholinesterase in honey bees (Apis mellifera) exposed to neonicotinoids, atrazine and glyphosate: Laboratory and field experiments. Environ. Sci. Pollut. Res. 20 (8), 5603-5614.

Branco, M. R., Kidd, N. A., Pickard, R. S., 2006. A comparative evaluation of sampling methods for Varroa destructor (Acari: Varroidae) population estimation. Apidologie 37 (4), 452-461.

Cremonez, T.M., De Jong, D., Bitondi, M.M.G., 1998. Quantification of hemolymph proteins as a fast method for testing protein diets for honey bees (Hymenoptera: Apidae). J. Econ. Entomol. 91 (6), 1284-1289.
De Jong, D., 2009. Pollen substitutes increase honey bee haemolymph protein levels as much as or more than does pollen. J. Apic. Res. 48 (1), 34-37.

DeGrandi-Hoffman, G., Curry, R., 2004. A mathematical model of Varroa mite (Varroa destructor Anderson and Trueman) and honeybee (Apis mellifera L.) population dynamics. Int. J. Acarol. 30 (3), 259-274.

Delaplane, K.S., Van Der Steen, J., Guzman-novoa, E., 2013. Standard methods for estimating strength parameters of Apis mellifera colonies. J. Apic. Res. 52 (1), 1-12.

Fluri, P., Wille, H., Gerig, L., Luscher, M., 1977. Juvenile hormone, vitellogenin and haemocyte composition in winter worker honeybees (Apis mellifera). Experentia 307 (1974), 1240-1241.

Fluri, P., Lüscher, M., Wille, H., Gerig, L., 1982. Changes in weight of the pharyngeal gland and haemolymph titres of juvenile hormone, protein and vitellogenin in worker honey bees. J. Insect Physiol. 28 (1), 61-68.

Free, J.B., Spencer-Booth, Y., 1959. The longevity of worker honey bee (Apis mellifera). Proc. R. Entomol. Soc. Lond. Ser. A Gen. Entomol. 34 (10-12), 141-150.

Gregorc, A., Alburaki, M., Werle, C., Knight, P.R., Adamczyk, J., 2017. Brood removal or queen caging combined with oxalic acid treatment to control varroa mites (Varroa destructor) in honey bee colonies (Apis mellifera ). Apidologie 48 (6), 821-832.

Harbo, J.R., 1983. Effect of population size on worker survival and honey loss in broodless colonie of honey bees, Apis mellifera L. (Hymenoptera: Apidae). Environ. Entomol. 12 (5), 1559-1563.

Havukainen, H., Münch, D., Baumann, A., Zhong, S., Halskau, Ø., Krogsgaard, M., Amdam, G. V., 2013. Vitellogenin recognizes cell damage through membrane binding and shields living cells from reactive oxygen species. J. Biol. Chem. 288 (39), 2836928381.

Haydak, M.H., 1970. Honey bee nutrition. Annu. Rev. Entomol. 15 (1), 143-156.

Huang, Z.-Y., Robinson, G.E., 1996. Regulation of honey bee division of labor by colony age demography. Behav. Ecol. Sociobiol. 39 (3), 147-158.

Maurizio, A., 1950. The influence of pollen feeding and brood rearing on the lenght of life and physiological condition of the honeybee. Bee World 31 (2), 9-12.

Münch, D., Kreibich, C.D., Amdam, G. V., 2013. Aging and its modulation in a long-lived worker caste of the honey bee. J. Exp. Biol. 216 (9), 1638-49.

Myers, M.J., Smith, E.R., Turfle, P.G., 2017. Biomarkers in veterinary medicine. Annu. Rev. Anim. Biosci. 5 (1), 65-87.

Nanetti, A., Büchler, R., Charrière, J., Friesd, I., Helland, S., Imdorf, A., Korpela, S., Kristiansen, P., 2003. Oxalic acid treatments for Varroa control. Apiacta 38 (1), 81-87.

Robbs, S.L., Ryan, R.O., Schmidt, J.O., Keim, P.S., Law, J.H., 1985. Lipophorin of the larval honeybee, Apis mellifera L. J. Lipid Res. 26 (2), 241-247. 
Rosenkranz, P., Aumeier, P., Ziegelmann, B., 2010. Biology and control of Varroa destructor. J. Invertebr. Pathol. 103 (SUPPL. 1), S96-S119.

Schulz, D.J., Huang, Z.Y., Robinson, G.E., 1998. Effects of colony food shortage on behavioral development in honey bees. Behav. Ecol. Sociobiol. 42 (5), 295-303.

Stevens, B.J., Hare, D.J., Volitakis, I., Cherny, R.A., Roberts, B.R., 2017. Direct determination of zinc in plasma by graphite furnace atomic absorption spectrometry using palladium/magnesium and EDTA matrix modification with high temperature pyrolysis. J. Anal. At. Spectrom. 32 (4):843-847.

van der Steen, J.J.M., Martel, A.-C., Hendrickx, P., 2016. The fraction haemolymph vitellogenin of a honey bee colony, derived from a pooled haemolymph sample, a colony vitality parameter. J. Apic. Res. 54 (1), 55-58.

Willott, E., Tran, H.Q., 2002. Zinc and Manduca sexta hemocyte functions. J. Insect Sci. 2 (1), 6. 